\title{
ESPAÇOS INSTITUCIONAIS DE SAÚDE COMO "NÃO LUGAR" DE TRAVESTIS NAS REPRESENTAÇÕES SOCIAIS DE ENFERMEIRAS
}

\author{
INSTITUTIONAL HEALTH SPACES AS "NO PLACE” \\ OF TRANSVESTITES IN THE SOCIAL \\ REPRESENTATIONS OF NURSES
}

\section{ESPACIOS INSTITUCIONALES DE SALUD COMO "NO LUGAR" DE TRAVESTIS EN LAS REPRESENTACIONES SOCIALES DE LAS ENFERMERAS}

\author{
Ester Mascarenhas Oliveira ${ }^{1}$ \\ Jeane Freitas Oliveira ${ }^{2}$ \\ Cleuma Sueli Santos Suto ${ }^{3}$ \\ Carle Porcino ${ }^{4}$ \\ Sara Peixoto Almeida ${ }^{5}$ \\ Daiane Santos Oliveira ${ }^{6}$
}

Como citar esse artigo: Oliveira EM, Oliveira JF, Suto CSS, Porcino C, Almeida SP, Oliveira DS. Espaços institucionais de saúde como "não lugar" de travestis nas representações sociais de enfermeiras. Rev baiana enferm. 2020;34:e35603.

\begin{abstract}
Objetivo: discutir a invisibilidade da pessoa travesti em instituições de saúde com base nas representações sociais de enfermeiras. Método: pesquisa qualitativa com abordagem téorica-metodológica das representações sociais que realizou entrevista semiestruturada com 20 enfermeiras matriculadas em cursos de pós-graduação de uma universidade pública. As informações coletadas foram processadas por meio do software Iramuteq, que gerou a Classificação Descendente Hierárquica com cinco classes. Resultados: identificou-se, no conteúdo representacional, que a invisibilidade das travestis está implicada no modo como profissionais de saúde percebem a necessidade/possibilidade de ocupação desses espaços, principalmente aqueles que ofertam atenção básica. Conclusão: as representações sociais das enfermeiras investigadas revelaram sentidos para a invisibilidade, exclusão, dificuldades no atendimento e dispensa de cuidados às travestis em instituições de saúde. A invisibilidade identificada nas representações das enfermeiras ocorre pelo modo como profissionais de saúde percebem a necessidade/possibilidade de ocupar esses espaços.
\end{abstract}

Descritores: Travestismo. Enfermeiras. Instituições de Saúde. Minorias Sexuais e de Gênero. Associação Livre.

\footnotetext{
Enfermeira. Mestra em Enfermagem. Docente do Curso de Enfermagem no Centro Universitário de Brasília. Brasilia, Distrito Federal, Brasil. https://orcid.org/00000002-6643-6910

Enfermeira. Mestra em Enfermagem. Doutora em Saúde Pública. Docente na Escola de Enfermagem da Universidade Federal da Bahia. Salvador, Bahia, Brasil. https://orcid.org/0000-0001-8401-8432.

Enfermeira. Mestra e Doutora em Enfermagem. Professora Assistente da Universidade do Estado da Bahia. Salvador, Bahia, Brasil. cleuma.suto@gmail.com. https://orcid.org/0000-0002-6427-5535.

Psicóloga. Mestra em Estudos Interdisciplinares. Universidade Federal da Bahia. Salvador, Bahia, Brasil. http://orcid.org/0000-0002-6I76-0 I 05.

Enfermeira. Pós-graduada em Enfermagem Obstétrica. Enfermeira Saúde da Mulher da Empresa Brasileira de Serviços Hospitalares. Salvador, Bahia, Brasil. http://orcid.org/0000-0002-6898-| 402.

Enfermeira. Mestra em Enfermagem. Universidade Federal da Bahia. Salvador, Bahia, Brasil. http://orcid.org/0000-0002-0252-44IX.
} 
Objective: to discuss the invisibility of the transvestite person in health institutions based on the social representations of nurses. Method: qualitative research with a theoretical-methodological approach of social representations that conducted a semi-structured interview with 20 nurses registered in postgraduate courses at a public university. The collected information was processed through the Iramuteq software, which generated the Hierarchical Descending Classification with five classes. Results: in the representational content, the invisibility of transvestites is implicated in the way health professionals perceive the need/possibility of occupation of these spaces, especially those who offer primary care. Conclusion: the social representations of the surveyed nurses revealed meanings for invisibility, exclusion, difficulties in care and care dispensation for transvestites in health institutions. The invisibility identified in the nurses' representations occurs by the way health professionals perceive the need/possibility to occupy these spaces.

Descriptors: Transvestism. Nurses. Health Facilities. Sexual and Gender Minorities. Free Association.

Objetivo: discutir la invisibilidad de la persona travesti en las instituciones de salud sobre la base de las representaciones sociales de las enfermeras. Método: investigación cualitativa con un enfoque teórico-metodológico de las representaciones sociales que realizó una entrevista semiestructurada con 20 enfermeras matriculados en cursos de postgrado en una universidad pública. La información recopilada se procesó a través del software Iramuteq, que generó la Clasificación Jerárquica Descendente con cinco clases. Resultados: se identificó, en el contenido representativo, que la invisibilidad de los travestis está implicada en la forma en que las profesionales de la salud perciben la necesidad/posibilidad de ocupación de estos espacios, especialmente aquellos que ofrecen atención primaria. Conclusión: las representaciones sociales de las enfermeras investigadas revelaron significados para la invisibilidad, exclusión, dificultades en la atención y dispensación de cuidados para travestis en instituciones de salud. La invisibilidad identificada en las representaciones de las enfermeras se produce por la forma en que las profesionales de la salud perciben la necesidad/posibilidad de ocupar estos espacios.

Descriptores: Transvestismo. Enfermeras. Instituciones de Salud. Minorías Sexuales y de Género. Asociación Libre.

\section{Introdução}

A saúde é determinada pela Constituição Brasileira de 1988 como "direito de todos e dever do Estado". A Política Nacional de Saúde Integral Lésbicas, Gays, Bissexuais, Travestis e Transexuais (LGBT), instituída em 2011, representa um marco na história de resistência e luta dessa população pela garantia de seus direitos. Sua formulação decorreu da participação ativa do movimento social organizado. Apesar dos avanços e das conquistas das pessoas transgêneras no que tange à agenda governamental, o que repercutiu, entre outros aspectos, na implantação de ambulatórios para pessoas transexuais e travestis em algumas capitais do Brasil, há de se considerar que pesa sobre a rede de serviços de saúde o desafio de produzir e incorporar tecnologias que contemplem as singularidades desse segmento.

Segundo dados da pesquisa "Diversidade Sexual e Homofobia no Brasil", realizada em 150 municípios, 25\% da população brasileira é homofóbica. Entre os participantes da pesquisa, 63\% apontou a qualificação de profissionais de saúde para atendimento de qualidade à população LGBT, como importante medida a ser adotada para combater a discriminação voltada a esse segmento ${ }^{(1)}$.

Assim, o acesso igualitário aos serviços e ações de saúde é uma demanda constante do movimento social organizado de pessoas Lésbicas, Gays, Bissexuais, Travestis, Trasexuais e Intersexo (LGBTI). Esse aspecto evidencia a necessidade de investimentos em processos de mudanças políticas, epistemológicas, técnico-assistenciais e socioculturais na forma como o setor saúde relaciona-se com a população transgênera. A construção de ações em saúde junto a essa população, admitindo seu protagonismo na produção de sua saúde, é um caminho para a materialização dos princípios constitucionais da equidade, integralidade, universalidade e justiça social do Sistema Único de Saúde (SUS) ${ }^{(2)}$. A esse respeito, no que se refere às pessoas transexuais e travestis, deve-se privilegiar o reconhecimento e o respeito às respectivas posições identitárias, 
considerando autodeterminação de gênero, tendo em vista as singularidades ${ }^{(3-4)}$.

Dentro do coletivo de pessoas LGBT, as travestis são dotadas de autenticidade e vivenciam uma feminilidade singular. Sua condição de população dissidente da normatividade de gênero hegemônica, pesa sobre suas vidas, colocando-as em situação de negação de direitos e, de forma geral, em diversos contextos de vulnerabilidades $^{(5)}$. Nesse sentido, as travestis são consideradas transgressoras de uma "norma social" que ainda naturaliza e privilegia uma linha congruente entre genitália-gênero-desejos e práticas sexuais como modelo de humanidade e moralidade, o que é denominado de (cis)heteronormatividade, sendo alvo de preconceitos, estigmas discriminação e exclusão. Esses aspectos, sobremaneira, potencializam as vulnerabilidades para agravos sociais e de saúde que podem repercutir na qualidade de vida ${ }^{(6-7)}$. Haja vista que, mesmo nos serviços especializados, considerados como os mais qualificados para o atendimento a esse segmento populacional, não é incomum a ocorrência de situações de discriminação vivenciadas por travestis quando acessam esses serviços ${ }^{(8-9)}$. Por esse ângulo, é primordial conhecer as representações sociais de profissionais de saúde e estudantes sobre travestis, visto que essas representações podem não corresponder ao modo como as pessoas se autodeterminam.

Nesse seguimento, o campo profissional de enfermeiras(os), à medida em que possibilite conhecer seu imaginário acerca das travestis, evidenciará nuances concernentes aos valores e às práticas sociais. Soma-se isso ao fato de ainda ser restrito o quantitativo de pesquisas que têm se dedicado a conhecer as nuances da relação entre as(os) enfermeiras(os) e as travestis, especialmente sobre o componente representacional dessa categoria profissional.

Neste estudo, a Teoria das Representações Sociais (TRS) apresenta-se como eixo norteador para a produção de saber sobre travestis. Desse modo, a escolha do objeto de pesquisa em questão permitiu acessar o pensamento de enfermeiras(os) a respeito do lugar da travesti no espaço institucional de saúde. Outrossim, as
Representações Sociais (RS) são construídas com base no simbólico das relações sociais, do vivido e dos saberes sociais, na medida em que facultam ao indivíduo ou ao grupo atribuir significados e sentidos, bem como a compreensão da realidade com base em seu sistema de referências ${ }^{(10)}$.

Assim, este estudo tem o objetivo de discutir a invisibilidade da pessoa travesti em instituições de saúde com base nas representações sociais de enfermeiras.

\section{Método}

Trata-se de uma pesquisa qualitativa, com foco na TRS, realizada com 20 enfermeiras, selecionadas mediante os seguintes critérios de inclusão: estar, no semestre 2015.1, matriculada em um dos cursos lato sensu ou stricto sensu oferecidos pelo Programa de Pós-Graduação da Escola de Enfermagem da Universidade Federal da Bahia (UFBA); ter participado de uma etapa prévia da pesquisa, em que se realizou o Teste de Associação Livre de Palavras (TALP), e ter experiência de pelo menos um ano em atividades assistencial, docência e/ou na gestão. Para a produção de informações, foi usada a técnica de entrevista semiestruturada guiada por um roteiro previamente elaborado com foco nos objetivos do estudo.

O número de entrevistadas foi definido pela repetição de informações acerca do objeto estudado. Nesse sentido, um número consensual de cerca de 20 até 30 entrevistas em estudos de investigação qualitativa pode ser considerado ${ }^{(11)}$. Para elaboração deste artigo, foram utilizadas as informações coletadas nas entrevistas realizadas no período de março a abril de 2016, em local previamente agendado, com duração média de 35 minutos.

Todas as participantes entrevistadas eram mulheres com idades entre 25 e 55 anos, com predominância para faixa etária de 25 a 35 anos. Dentre as participantes, 18 declararam ser de cor parda, 16 professavam a religião católica e tinham vínculo empregatício no momento da produção de dados e 12 atuavam na assistência e na docência. 
As entrevistas foram realizadas em local previamente agendado, tiveram duração média de 35 minutos e seu conteúdo foi transcrito na íntegra. Para a análise dos dados, foi utilizado o software Iramuteq alpha 2, que realiza, dentre outras, a análise de conteúdo do tipo Lexical, por meio do contexto de um Conjunto de Segmentos de Texto que conformou a Classificação Hierárquica Descendente (CHD). O Iramuteq é uma ferramenta que possibilita a análise de dados textuais e permite realizar análise de conteúdo presente no texto por meio de estatística textual $^{(12)}$. Os dados das entrevistas foram inseridos neste software para a obtenção de uma série de procedimentos estatísticos aplicados a bancos de dados textuais.

Assim, a análise alcançada pelo programa classifica os enunciados por meio da comparação dos perfis lexicais, o que delimita a separação lexical. Após a divisão em enunciados, caberá ao pesquisador a recuperação dos elementos que interessam com base no objeto de estudo delimitado ${ }^{(13)}$. As entrevistas foram demarcadas pela inserção de uma linha de comando, tendo como variável apenas as participantes. Esta linha de comando delimita também o início de cada unidade a ser analisada e denomina-se "unidade de contexto inicial (UCI)", por meio da qual o software origina as diferentes classes e gera a forma gráfica do dendograma.

O projeto de pesquisa que originou este artigo foi aprovado pelo Comitê de Ética da Escola de Enfermagem da Universidade Federal da Bahia, por meio do Parecer $n^{\circ}$ 1.203.257.
Durante o desenvolvimento da pesquisa, buscou-se atender a todos os princípios éticos estabelecidos pela Resolução n ${ }^{\circ} 466 / 2012$, do Conselho Nacional de Saúde. Todas as participantes assinaram o Termo de Consentimento Livre e Esclarecido e foram advertidas sobre a vigência de uma atividade de participação facultativa e a não existência de benefícios materiais ou financeiros. Em respeito aos princípios éticos, especialmente quanto ao anonimato das participantes e ao sigilo das informações prestadas, cada pessoa foi identificada pela letra "E" seguida do número de ordem de realização da entrevista.

\section{Resultados}

O corpus foi composto por 58 segmentos de texto, 612 formas distintas e frequência média maior ou igual a 3,98 para cada forma. A análise de CHD incidiu sobre 78,3\% do material recolhido, permitindo a descrição de conteúdos discursivos advindos das entrevistas. Estes evidenciaram dimensões das representações sociais de enfermeiras, com a geração de cinco classes ou categorias de análise. Observa-se, na distribuição destas classes, que a classe 4 agregou o maior número de termos, correspondendo a 23,5\% do conteúdo. No entanto, o quantitativo de UCI entre as classes apresentou-se de forma relativamente equitativa. A CHD possibilitou a análise dos parâmetros de divisão das classes e definição dos eixos temáticos que geraram as classes assentadas nas relações de dependência estabelecidas entre si (Figura 1). 
Figura 1 - Dendograma das representações sociais de enfermeiras sobre a invisibilidade de travestis em instituições de saúde

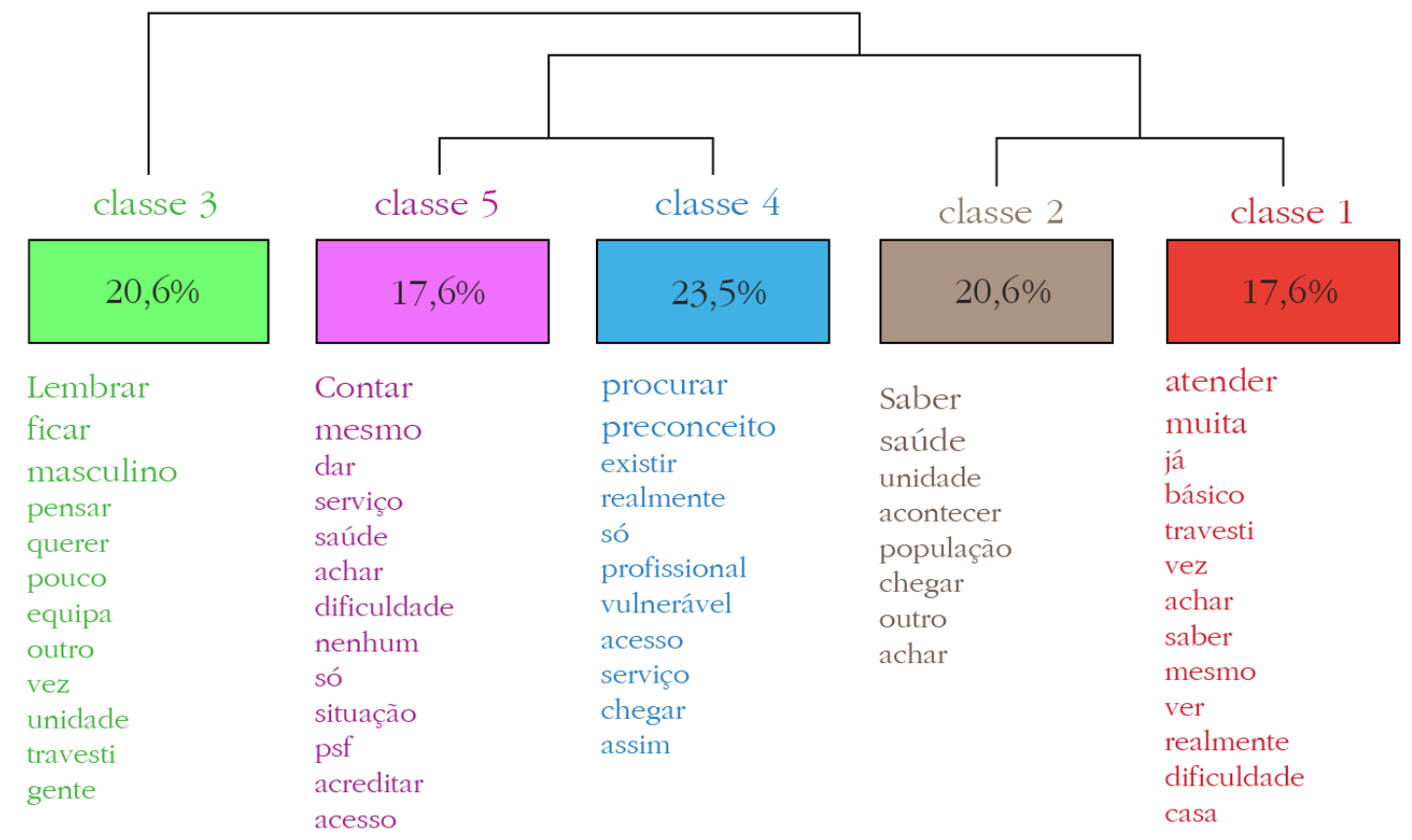

Fonte: Elaboração própria.

A descrição dos dados, conforme as partições presentes no dendograma (Figura 1) da CHD, demarcou a construção de três eixos temáticos: o primeiro formado pela classe 3; o segundo pelas classes 4 e 5 e, de forma mais distante, o terceiro eixo formado pelas classes 1 e 2. Assim, optou-se por empregar os seguintes termos para denominar cada eixo: 1 - "lembra após pensar sobre"; 2 - "o preconceito como barreira para o acesso aos serviços de saúde"; e 3 - "o "não saber' como atender".

Os três eixos reúnem aspectos relativos à "invisibilidade" e demarcam dimensões da RS que abarcam o pessoal, o social e o relacional. O primeiro evidencia que as profissionais participantes do estudo sequer lembraram quando atenderam uma travesti, ou mesmo se já atenderam; o segundo agrupa questões relativas às barreiras enfrentadas por travestis no acesso e/ou na procura aos serviços de saúde e perpassa pelo enfrentamento de situações de preconceito e discriminação; enquanto que o terceiro evidencia as dificuldades enfrentadas por enfermeiras no âmbito dos serviços de saúde, no que se refere ao acolhimento, atendimento e cuidados dispensados às travestis.

O eixo 1, classe 3 - "lembra após pensar sobre" consolida-se nos relatos das enfermeiras entrevistadas:

\footnotetext{
Lembro que o médico que a atendeu na emergência, a tratou super mal. Ela tinha um abcesso mamário, devido ao extravasamento do silicone que tinha acontecido [...] (E12).

Trabalhei dois anos no PSF e no hospital, mas nunca aconteceu de chegar a mim nenhuma e também não no PSF. Durante visitas e outras atividades que fazia não conheci nenhuma [travesti] na comunidade que trabalhava. (E13).

[...] lembro que essa travesti trabalhava na noite como prostituta e tinha ido buscar preservativo pra usar no trabalho. Foi uma relação muito tranquila, depois ela retornou ainda me levou umas frutas. (E2).
}

No eixo 2, classes 4 e 5 , "o preconceito como barreiras para o acesso aos serviços de saúde" evidenciada por meio dos discursos das enfermeiras. As profissionais reconheceram que as travestis vivenciavam situações de preconceito que resultavam em discriminação. Também revelaram que há uma busca por diferenciar sua prática de cuidado daquela oferecida pelos demais profissionais: 
Ainda existe esse preconceito muito grande. Então, quando essas pessoas chegam, porque muitas vezes elas nem procuram o serviço, observo que elas não procuram o serviço justamente pela violência que sofrem e pelo preconceito. Porque as pessoas [enfermeiras] não querem cuidar. (E1).

Às vezes tem o afastamento deles do serviço, porque os olhares são preconceituosos, mas que já entendo que também tem uma luta porparte deles de buscar melhorar, de forma tímida, porque acho que esse grupo, essas pessoas travestis poderiam ser até um pouco mais ousadas nessa questão por busca por saúde. (E10).

Acho que a dificuldade de acessar esses serviços de saúde [leva] a dar jeitinhos, tomando medicação por conta própria, fazendo as coisas em serviços clandestinos, ou por conta própria, de maneira empírica e só em última situação buscar um serviço de saúde. (E4).

Em situações de dois atendimentos [às travestis], em que eu e outra colega tivemos a preocupação de dar um cuidado dentro dos direitos da pessoa [travesti]. (E8).

Acho que isso acontece porque, quando fui da assistência, atuei na unidade de saúde da família e, infelizmente, a gente sabe que algumas populações vulneráveis, como travestis, prostitutas, moradores de rua, eles não chegam às unidades de saúde porque normalmente as unidades de saúde fecham as portas para essas pessoas [...] (E5).

O eixo 3, composto pelas classes 1 e 2, denominado "o 'não saber' como atender", está relacionado às ações de cuidado em saúde que deveriam contemplar as demandas desse segmento populacional, considerando suas especificidades. Entretanto, boa parte mencionou o "desvio sexual", evidenciando o desconhecimento sobre as travestilidades, e/ou apontou ações pontuais para a atenção, o que nem sempre produz desfechos favoráveis a longo prazo, como pode ser observado nos trechos a seguir:

Não vejo as travestis em serviços. Não sei se existem serviços especializados para elas [...] Tenho pouco tempo de formada. (E9).

Na atenção primária, pensando na prevenção, não há espaço para esse outro usuário, ou ele é homem ou ele é mulber. Ele está no pré-natal ou ele está no grupo de hipertenso ou de homens, na condição de homem, então não há espaço. (E6).

Nunca atendi algum travesti. É porque não chega aos serviços de saúde. (E10).

\section{Discussão}

Os três eixos contêm elementos que se sobrepõem na elaboração de uma representação social, sobretudo quando se trata de um objeto norteado por questões sociais, culturais e morais que se entrelaçam com questões éticas e religiosas que dizem respeito à sexualidade. Dessa forma, os elementos que compõem os eixos de análise reverberam em um dos princípios da Teoria das Representações Sociais, na medida em que reproduz o pensamento social, fundado em mitos, crenças, ideologias, opiniões e atitudes, que pode ser transformado ao longo de um tempo com base em experiências pessoais e sociais.

Pelos relatos, a presença da pessoa travesti nos espaços instituicionais de saúde nos quais as entrevistadas atuavam constitui uma situação rara, uma vez que precisaram recorrer à memória para acessar registros de contatos esporádicos. Essa ausência e/ou raridade de presença da pessoa travesti nos serviços de saúde denuncia o desrespeito a um direito humano básico aprovado na Constituição Federal: direito à saúde.

A Carta dos Direitos dos Usuários da Saúde, aprovada pela Portaria MS/GM nº 675, de 30 de março de 2006, reafirma o respeito ao nome social, além de assegurar o atendimento humanizado e livre de preconceito e discriminação por orientação sexual e identidade de gênero ${ }^{(14)}$. Embora passados mais de 14 anos desde a publicação dessa Carta, persiste a dificuldade na efetivação desses direitos, como sinalizam as falas das participantes que, em sua maioria, têm menos de 30 anos de idade.

Nesse sentido, foi possível constatar que as participantes do estudo reconheciam a existência de barreiras enfrentadas por travestis nas instituições públicas de saúde, em decorrência do desconhecimento, por parte de profissionais de saúde, dos problemas que as afetavam, dentre os quais incluem-se, a falta de resolutividade, o não respeito à sua expressão e identidade de gênero e ao nome social (para aquelas que ainda não retificaram civilmente) no momento do atendimento, entre outros. As travestis sentem-se incomodadas pela forma como são tratadas, pelo julgamento moral e pela distância denunciada pelos gestos, olhares e falas dos profissionais que as atendem nos serviços de saúde ${ }^{(9,15)}$. 
As lembranças de algumas enfermeiras, acerca do atendimento, do acolhimento e dos cuidados dispensados reafirmam que o preconceito gera o cenário de tensões e violência, na medida em que afasta as travestis dos serviços de saúde e dos diversos espaços institucionais. O preconceito é uma forma ativa de desumanizar e reforçar práticas excludentes, pois está mais relacionado a valores morais e práticas sociais que violam direitos humanos básicos ${ }^{(3,6,8-9)}$.

No segmento LGBTI, um possível movimento para enfrentar o preconceito, a discriminação e a violação de direitos básicos é a criação de estratégias de cuidado para as travestis, tendo como foco a identificação de suas demandas de saúde, em consonância com o que preconiza o movimento social organizado. Trata-se, portanto, de não pensar apenas em seus corpos ou em sua localização social (onde vivem, onde trabalham, como dormem etc.), mas inclui as práxis que facultam a organização do trabalho das enfermeiras. Nesse sentido, a reflexão, por parte das enfermeiras, acerca das singularidades que envolvem as diversas formas de existência, pode contribuir para um cuidado singularizado voltado a esse segmento ${ }^{(6)}$.

No eixo 2, estão presentes as falas que revelam como o preconceito fundado na discriminação constitui-se na principal barreira para o acesso aos serviços de saúde. Nas classes 4 e 5 desse eixo, foram identificados, no conteúdo representacional das participantes do estudo, fatores culturais relacionados ao modo de atuar dessas profissionais e aqueles da própria estrutura organizacional dos serviços de saúde, que contribuem para o distanciamento dessa população das unidades de saúde. As profissionais, em suas falas, relataram que as travestis eram pessoas que sofriam preconceito pelos diversos profissionais da equipe e, por isso, nem sempre conseguiam transpor as barreiras para o acesso às instituições de saúde na tentativa de solucionar suas demandas.

A necessidade de sensibilização junto aos profissionais da saúde para o atendimento não discriminatório da população LGBTI ainda é um dos temas mais recorrentes nos debates sobre as políticas públicas de saúde formuladas para esses segmentos. A opinião é a mesma entre gestores e ativistas em relação ao alcance das ações de sensibilização de agentes de saúde, no que diz respeito aos danos individuais e sociais decorrentes da transfobia, constatando-se que ainda há muito por fazer, já que as iniciativas e o público alcançado são pouco significativos ${ }^{(16)}$.

A dificuldade de profissionais da equipe de saúde vai desde a definição da enfermaria para admissão de uma paciente transgênera, na situação de internamento, à forma como dirigir-se à paciente, em respeito ao seu nome social. Essas situações ilustram cenas do cotidiano de profissionais de saúde e das travestis nos serviços públicos em geral. No entanto, deve-se atentar para o fato de que tais vivências podem interferir tanto no cuidado prestado como repercutir na qualidade de vida das travestis ${ }^{(17)}$. Dessa meneira, também é essencial suscitar reflexões em torno dos limites e desafios na realizações dessas ações, para que sejam apontadas e/ou elaboradas junto às travestis, com vistas a conhecer as especificidades, demandas de saúde e cuidados apoiados nos discursos que circulam entre elas próprias ${ }^{(18)}$.

As condições de vulnerabilidades que fazem parte do contexto de vida das travestis, em especial a violência e o preconceito, produzem situações de agravamento em sua condição de saúde. As leis relativas à assistência/cuidado vêm sendo descumpridas, negligenciadas e violadas, há mais de uma década. Assim, a existência de barreiras que impossibilitam as travestis de alcançarem as ações de educação, prevenção e promoção da saúde, influenciam na opção pela automedicação relacionada ao uso de hormônios e pela utilização do silicone líquido industrial, com vista à conformação do corpo, o que contribui sobremaneira nos processos de autoafirmação e elevação da estima. Esse fato decorre também da dificuldade econômica de acessar a rede suplementar, para realizar o processo de acompanhamento médico. Este aspecto pode influenciar na automedicação e na adoção de práticas de modificação/alteração corporal 
que podem potencializar riscos e comprometer a saúde e a qualidade de vida ${ }^{(3,9,15)}$.

A concepção cisheteronormativa deu vida a um modelo de funcionamento sob o qual as relações, as pessoas, os objetos e os ambientes estruturam-se. Por esse ângulo, quem foge à regra é posto à margem, no terceiro plano, na periferia e na precarização da vida. Desse modo, viver fora do padrão binário é algo insuportável à sociedade cisheteronormativa, que, neste caso, constrói e utiliza engrenagens para subjugar, punir e enquadrar as pessoas que ainda são vistas e classificadas como "diferentes"(19). Assim, na medida em que pessoas são excluídas do meio social pelo fato de suas vivências não corresponderem ao padrão que a sociedade impõe, imputa-se-lhes uma espécie de condenação, que não só as abandonam à própria sorte, como também buscam infligir-lhes violências e violação de direitos em nome da ética ${ }^{(20)}$.

Sociocultural e historicamente, foi "[...] construída a noção de que existe a 'verdadeira' identidade sexual e que ela está associada ao "verdadeiro' sexo, que é considerado o biológico"(21:85). Portanto, indivíduos com sexualidade "divergente" da normativa cisheterossexual, na qual vigoram posições binárias de gênero (masculino/feminino, macho/fêmea), ainda são vistos como "anormais". No que se refere às travestis, o fato de seus gêneros ainda serem vistos e/ou concebidos como "não inteligíveis" inexiste a possibilidade de estabelecimento de relações de coerência entre sexo, gênero, prática sexual e desejo $^{(22)}$.

A orientação sexual e a identidade de gênero são dimensões distintas da vida humana que podem potencializar as vulnerabilidades da população LGBTI no que se refere a agravos à saúde e repercussão na qualidade de vida decorrentes de enfrentamento ao estigma, ao preconceito e à discriminação. Como exemplo, pode-se citar a não continuidade, por parte das travestis, do tratamento de doenças crônicas e dificuldade de acesso aos serviços de saúde, por receio de serem expostas a processos discriminatórios e de exclusão que violam os direitos humanos, entre os quais o direito à saúde ${ }^{(23)}$. Nesse sentido, a desapropriação dos espaços institucionais produz a invisibilidade para aquelas que se autorreferem travestis.

Ainda que sejam percebidas condições mais favoráveis, no âmbito institucional, para o respeito às identidades de gêneros e o reconhecimento das diferenças, as transformações das redes de saúde requerem um investimento considerável, pois dependem de transformações no modo de pensar e de agir de profissionais de saúde. As questões simbólicas advindas do padrão cisheteronormativo influenciam de modo objetivo o atendimento dispensado por profissionais da saúde às travestis ${ }^{(5)}$.

É relevante atentar-se para a conduta da Enfermagem frente às travestis. Estudo ${ }^{(24)}$ aponta que o comportamento das enfermeiras, na atenção às travestis, merece reflexão, pois fica evidente o seu pouco comprometimento e preparação para o atendimento, sobretudo no que diz respeito às especificidades trazidas por elas. Traz preocupação o fato de que o perfil de atenção que tem se conformado para a população de travestis vai de encontro ao que preconiza a Política Nacional de LGBT, o que, por revés, fortalece as representações hegemônicas que resultam no distanciamento, por parte de pessoas desse segmento, dos espaços de cuidado.

Assim, o olhar sensível e cuidadoso voltado para a população transgênera poderá contribuir sobremaneira para a transformação das relações sociais pautadas na horizontalidade e para a efetividade e equidade do SUS ${ }^{(25)}$. Vale salientar que ainda é incipiente a produção científica pautada nas representações sociais, no que se refere às pessoas transgêneras ${ }^{(24-25)}$.

Desse modo, pode-se inferir que os elementos que compõem as RS das enfermeiras estão pautadas nesse contexto, que, além de nocivo e excludente, implica na invisibilidade que ainda se impõe aos modos de ser/estar travesti. Esse segmento enfrenta barreiras de socialização no cotidiano das cidades, em instituições escolares, nas ruas e no dia a dia dos serviços de saúde. Essa condição impulsiona essas pessoas para o que foi denominado de "não lugar", pois, nesse espaço desprivilegiado não há vez, voz ou 
oportunidade, mas tão somente seguir a norma que ainda é hegemônica, injusta, desumana e excludente para com as diferenças.

O estudo sobre representações sociais ocupa-se da análise do conhecimento produzido no cotidiano, isto é, do processo de construção da realidade com base nas relações sociais. Enquanto estudo científico do senso comum, a Teoria das Representações Sociais considera que o conhecimento modifica-se conforme inserções específicas num contexto de relações sociais ${ }^{(10,24)}$. Assim, pelo seu caráter normativo/prescritivo, ao orientar as práticas sociais das enfermeiras, serve de guia para ações e relações sociais e de cuidado no ambiente institucional.

A limitação deste estudo envolve a participação de enfermeiras discentes de único programada de pós-graduação. No entanto, os resultados possibilitaram visibilizar elementos importantes para o (re)pensar e o (re)fazer da enfermagem de uma Escola que é vanguarda da história da enfermagem brasileira. A carência de estudos sobre a temática difucultou o estabelecimento de relações entre os achados da pesquisa e a realidade de profissionais em distintos contextos nacionais.

\section{Conclusão}

As representações sociais das enfermeiras investigadas revelaram sentidos para a invisibilidade, exclusão, dificuldades no atendimento e dispensa de cuidados às travestis nos serviços de saúde, aspectos que repercutem negativamente na adesão às propostas de atenção ofertadas atualmente. A invisibilidade das travestis, identificada nas representações das enfermeiras, ocorre pelo modo como profissionais de saúde e travestis percebem a necessidade/possibilidade de ocupar esses espaços.

Reconhecer a invisibilidade das travestis nos espaços instituicionais de saúde, embora limitado a um grupo de enfermeiras, provocou discussões no espaço acadêmico e laboral das participantes. Ademais, a divulgação desse dado pode constituir-se em elemento de reflexão e discussão para outros grupos de profissionais, possibilitando uma aproximação com a temática, de modo a dar visibilidade às pessoas travestis e a todas aquelas que não atendem ao modelo cisheteronormativo.

O lugar e o destino das travestis precisam ser construídos, de início, no imaginário das pessoas, o que, prevê-se, envolve uma disputa ideológica por uma não-normatividade para a sexualidade humana. Nesse campo, pela importância da enfermagem na concepção, gerenciamento e operacionalização do cuidado, é premente refletir sobre o seu papel e o seu compromisso na construção de condições que permitam às travestis o exercício do seu direito à saúde e à qualidade de vida.

Assim, a formação de profissionais de saúde centrada no cuidado precisa estar comprometida pelo respeito às diferenças. O trabalho em saúde que não primar pelo respeito ao ser humano enquanto pessoa que é diferente e singular poderá suscitar barreiras de acesso e qualidade na atenção à saúde, além de negligenciar direitos, como no caso das travestis.

\section{Colaborações:}

1 - concepção, projeto, análise e interpretação dos dados: Ester Mascarenhas Oliveira e Jeane Freitas Oliveira;

2 - redação do artigo e revisão crítica relevante do conteúdo intelectual: Ester Mascarenhas Oliveira, Jeane Freitas Oliveira, Cleuma Sueli Santos Suto, Carle Porcino, Sara Peixoto Almeida e Daiane Santos Oliveira;

3 - aprovação final da versão a ser publicada: Ester Mascarenhas Oliveira, Jeane Freitas Oliveira e Cleuma Sueli Santos Suto.

\section{Referências}

1. Venturi G. Diversidade Sexual e Homofobia no Brasil: intolerância e respeito às diferenças sexuais [Internet]. São Paulo: Fundação Perseu Abramo; 2010 [cited 2018 Oct 7]. Available from: https:// fpabramo.org.br/2010/02/13/diversidade-sexuale-homofobia-no-brasil-intolerancia-e-respeito-asdiferencas-sexuais/ 
2. Rocon PC, Zamboni J, Sodré F, Rodrigues A, Roseiro MCFB. (Trans)formações corporais: reflexões sobre saúde e beleza. Saude soc. 2017;26(2):521-32. DOI: http://dx.doi.org/10.1590/ s0104-12902017171907

3. Porcino C, Coelho MTÁD, Oliveira JF. Travesti(s)lidades: representações sociais de universitários. Curitiba: Appris; 2020.

4. Facchini R, Calazans GJ, França IL, Gambôa RF, Puccinelli B, Redoschi B, et al. "A prevenção não sobe a Augusta": homossexualidade, HIV, "risco" e produção de fronteiras na região central da cidade de São Paulo. Sex Salud Soc. 2018;29:340-72. DOI:https://doi.org/10.1590/1984-6487.sess.2018.29.16.a

5. Cardoso MR, Ferro LF. Saúde e população LGBT: demandas e especificidades em questão. Psicol cienc prof. 2012;32(3):552-63. DOI: http://dx.doi. org/10.1590/S1414-98932012000300003

6. Oliveira EM, Oliveira JF, Porcino C, Campos LCM, Reale MJOU, Souza MRR. "Corpo de homem com (tre)jeitos de mulher?": imagem da travesti por enfermeiras. Interface. 2019;23:e170562. DOI: http://dx.doi.org/10.1590/interface.170562

7. Porcino CA, Coelho MTÁD, Oliveira JF. Representações sociais de universitários sobre a pessoa travesti. Saude soc. 2018;27(2):481-94. DOI: http://dx.doi.org/10.1590/s0104-12902018169303.17

8. Porcino C, Suto CSS, Silva DO, Almeida-Junior JA, Coelho MTÁD, Oliveira JF. A pessoa travesti e a/o profissional de enfermagem: percepção de humanização e do respeito à expressão e identidade de gênero. In: Monteiro SAS, organizador. Sexualidade e relações de gênero. [Internet]. Ponta Grossa: Atena; 2019. p. 77-84 [cited 2019 Dec 2]. Availabe from: https://www.atenaeditora. com.br/wp-content/uploads/2019/09/E-bookSexualidade-e-Relacoes-de-Genero-3.pdf

9. Monteiro S, Brigeiro M. Experiências de acesso de mulheres trans/travestis aos serviços de saúde: avanços, limites e tensões. Cad Saúde Pública. 2019;35(4):e00111318. DOI: https://doi. org/10.1590/0102-311x00111318.3

10. Moscovici S. Representações sociais: investigações em psicologia social. 11a ed. Petrópolis: Vozes; 2015.

11. Minayo MCS. Amostragem e saturação em pesquisa qualitativa: consensos e controvérsias. Rev Pesqui Qual [Internet]. 2017 [cited 2019 Oct 10];5(7):1-12. Available from: https://editora.sepq.org.br/index. $\mathrm{php} / \mathrm{rpq} / \mathrm{article} / \mathrm{view} / 82 / 59$
12. Loubère L, Ratinaud P. Documentation IRaMuTeQ. 0.6 alpha 3. Version 0.1 [Internet]. Toulose (FR); 2014 [cited 2018 Dec 11]. Available from: http://www.iramuteq.org/documentation/fichiers/ documentation_19_02_2014.pdf

13. Oliveira DC, Marques SC, Gomes AMT, Teixeira MCTV. Análise das evocações livres: uma técnica de análise estrutural das representações sociais. In: Moreira ASP, Camargo BV, Jesuíno JC, Nóbrega SM, organizadores. Perspectivas teórico-metodológicas em representações sociais. João Pessoa: Editora UFPB; 2005. p. 573-602.

14. Brasil. Ministério da Saúde. Carta dos direitos dos usuários da saúde. 2a ed. Brasília; 2006. (Série E. Legislação de Saúde).

15. Souza MH, Malvasi P, Signorelli MC, Pereira PPG. Violência e sofrimento social no itinerário de travestis de Santa Maria, Rio Grande do Sul, Brasil. Cad Saúde Pública. 2015;31(4):767-76. DOI: http://dx.doi.org/10.1590/ 0102-311X00077514

16. Mello L, Perilo M, Albuquerque BC, Pedrosa C. Políticas de saúde para lésbicas, gays, bissexuais, travestis e transexuais no Brasil: em busca de universalidade, integralidade e equidade. Sex Salud Soc. 2011;9:7-28. DOI: http://dx.doi. org/10.1590/S1984-64872011000400002

17. Petry AR. Mulheres transexuais e o Processo Transexualizador: experiências de sujeição, padecimento e prazer na adequação do corpo. Rev Gaúcha Enferm. 2015;36(2):70-5. DOI: http:// dx.doi.org/10.1590/1983-1447.2015.02.50158

18. Teixeira FB, Paulino DB, Raimondi GA, Crovato CAS, Prado MAM. Entre o segredo e as possibilidades do cuidado: (re)pensando os silêncios em torno das narrativas das travestis sobre HIV/AIDS. Sexualidad, Salud y Sociedad [Internet]. 2018 [cited 2020 Feb 1];(29):373-88. Available from: https://doi.org/10.1590/1984-6487. sess.2018.29.17.a

19. Santos AS. O gênero encarnado: modificações corporais e riscos à saúde de mulheres trans. [tese]. Rio de Janeiro (RJ): Universidade Estadual do Rio de Janeiro; 2014.

20. Butler J. Relatar a si mesmo: crítica da violência ética. Belo Horizonte: Autentica; 2017.

21. Butler J. Problemas de gênero: feminismo e subversão da identidade. Rio de Janeiro: Civilização Brasileira; 2003. 
22. Gianna MC. CRT DST/Aids-SP implanta primeiro ambulatório para travestis e transexuais do país. BIS, Bol Inst Saúde [Internet]. 2011 [cited 2018 Feb 12];13(2):182-9. Available from: http://periodicos.ses.sp.bvs.br/scielo.php? script $=$ sci_arttext $\&$ pid $=$ S1518 -18122011000 200013\&lng=pt\&nrm=iso

23. Nunes JFC, Albuquerque GA, Nunes JFC, Belém JM, Leite MF, Sousa-Neto AA. Representações da assistência de enfermagem voltada para o atendimento de Lésbicas, Gays, Bissexuais, Travestis, Transexuais e Transgêneros (LGBTS). In: Semana de Iniciação Científica da Faculdade de Juazeiro do Norte, 5, 2013, Fortaleza, CE. Anais [on-line]. Fortaleza (CE): Faculdade de Juazeiro do Norte; 2013 [cited 2018 Jul 14]. Available from: http://www.fjn.edu. br/iniciacaocientifica/anais-v-semana/trabalhos/ simples-oral/EN0000000511.pdf

24. Moreira MA, Gomes AJM. Representações Sociais de estudantes concluintes de enfermagem sobre transexualidade. Rev Enferm UFPE [Internet]. 2013 [cited 2019 Apr 10];7(5):4378-88. Available from: http://www.revista.ufpe.br/revistaenfermagem/ index.php/revista/article/download/4471/6390

25. Borges CA, Souza M. Saúde das travestis: um desafio para a enfermagem [trabalho de conclusão de curso]. Santa Maria (RS): Centro Universitário Franciscano; 2012.

Recebido: 2 de março de 2020

Aprovado: 15 de junho de 2020

Publicado: 5 de outubro de 2020

A Revista Baiana de Enfermagem utiliza a Licença Creative Commons - Atribuição-NãoComercial 4.0 Internacional.

https://creativecommons.org/licenses/by-nc/4.0/

Este artigo é de acesso aberto distribuído sob os termos da Licença Creative Commons (CC BY-NC).

Esta licença permite que outros remixem, adaptem e criem a partir do seu trabalho para fins não comerciais. Embora os novos trabalhos tenham de lhe atribuir o devido crédito e não possam ser usados para fins comerciais, os usuários não têm de licenciar esses trabalhos derivados sob os mesmos termos. 